\title{
Study on the Reform and Innovation of Enterprise Performance
}

\section{Management}

\author{
Li Fangjing \\ Xi'an International University, Xi'an, 710077, China \\ 346591653@163.com
}

Keywords: enterprise; performance management; reform; concept; goal; object

\begin{abstract}
: with the emergence of innovative management ideas, in order to adapt to the trend of the times, the performance management is experiencing the process of continuous improvement and change, and it plays an irreplaceable role in human resource management system. Performance management is one of the most important part of production management of the enterprise, so it is very important to the enterprise overall management effect and the economic and social benefits. Based on the author's work experience, this paper discusses the method of reform and innovation from performance management concept, goal and object.
\end{abstract}

\section{Introduction}

Performance management strengthens the linkages with other management functions requires business managers from a strategic height, with effective integration of performance management, to work together to promote improvement in corporate performance. Performance management needs to expand and enrich the original concept, with innovative tools and methods to meet the needs of modern enterprise management evolving. For this, it needs to explore the remarkable change and innovation of performance management research in recent years.

\section{The Reform and Innovation of Performance Management Concepts}

In concept, performance management has experienced the changes from the traditional performance appraisal to comprehensive, strategic performance management. In the early days in the eyes of business owners, employees, equipment and plant are the same, they are merely a tool to create profits, must try to save and control labor costs; In the eyes of the staff, himself as an employee, is purely economic and employment relationship between business owners, so he also does not want to take the initiative to care about the development of enterprises. Therefore, in the management of employees, business owners set a lot of regulations to control the behavior of employees in order to reduce costs. Strategy-oriented performance management system is a system that promotes all-round business contact occurs and timely monitor in the planning, organization, control and all other management activities. Its main activities include two aspects: First, establish a scientific and standardized performance management system based on corporate strategy, make strategy-center to pull the enterprise business activities; Second, according to the relevant performance management system to review each of the performance management cycle and then to take the management team or responsible for the object to evaluate the performance. The value distribution based on the evaluation results is shown in Fig.1. 


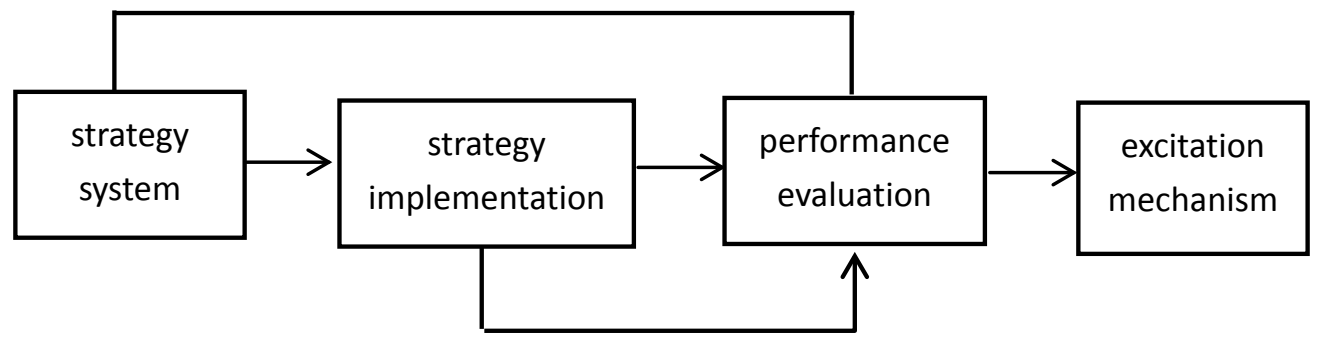

Fig.1 Strategic Performance Management Design Ideas

Strategic performance management system has the following characteristics: First, focus on long-term strategic business goals, as a kind of traction, long-term goals will guide the performance management; Second, focus on a full range of business goals, and this is the basis of a strategic performance management system; Third, the strategic goals are put down to every level to the various departments, ultimately to implement each employee to each post; Fourth, it emphasizes both process and results; Fifth, the major corporate decisions must take into account the degree of realization of performance.

\section{The Reform and Innovation of Performance Management Goals}

On the goals, performance management has undergone changes. Initial target is to improve employee performance level, then the goal is to improve employee input. While previous performance management system regard the continuing to improve the performance level of employees as well as to improve the organization's overall performance as the goal, in the actual application process, it is still difficult to avoid performance management activities in the form of floating phenomenon. For example, to avoid touching interests disputes, the performance evaluation results are too convergence, which will not pull out a gap. At the same time, performance management emphasizes monitoring for the work process and focusing on results and this will increase the workload of the respective performance management participants, causing a $\mathrm{i}$ intensive employment relationship. Therefore, while the current performance management system provides a very good idea to improve organizational efficiency, management tool itself has a lack of incentive and mandatory administrative malpractice. Resulting in performance management and has been difficult to implement in a passive state. How to motivate employees and leaders to make the performance management itself have with resistance is the performance management innovation focus.

Work engagement refers to positive emotional and cognitive status and work-related, including the energy, dedication and focus. Studies have shown that employees with a high degree of job involvement has a higher cognitive work, and they will put existing work among the positive state, and can significantly improve the performance level of employees and it can significantly improve the performance levels of employees, reduce turnover intention. Based on the above ideas, Canadian scholar Gruman and Saks from the perspective of job commitment, integrating the individual and the whole, micro and macro, and then they proposed management system model, designed to improve and increase employee job involvement, and promote the performance management efficiency. 
In the classical performance management PDCA cycle process, this model incorporates content increasing employee investment management, that is, by driving the individual employee's work to promote investment to drive the entire performance management process. First, in accordance with the process of management by objectives, it makes employees have a clear understanding for the enterprise performance plans and objectives, and obtains employees and business agree. This psychological contract built on the stabilization target consistent basis is an important prerequisite to enhance employee job commitment. Second, in the implementation, which is the core part of the work performance management, enterprises should use all the resources and support to promote job commitment. For example, using job analysis way to structure people post match, encourage and create an inclusive style.

\section{The Reform and Innovation of Performance Management Objects}

Team-based performance management. Dynamic management environment and the nature of the work focusing on cooperation gave birth to the enterprise division in the form of a team as a unit, and it is common in modern business management practices. Team-based performance management is also an important direction of innovative performance management theory and practice. Team performance only emphasizes the results of the work of the team, the team also searched for the collaborative process. Naler considered team performance, including the reaching situation of the established goals, job satisfaction of team members and the ability to continue to develop. Meanwhile, the team's performance output also contains a number of factors, many affected by the "input - cooperation - output" process (see Figure 2).

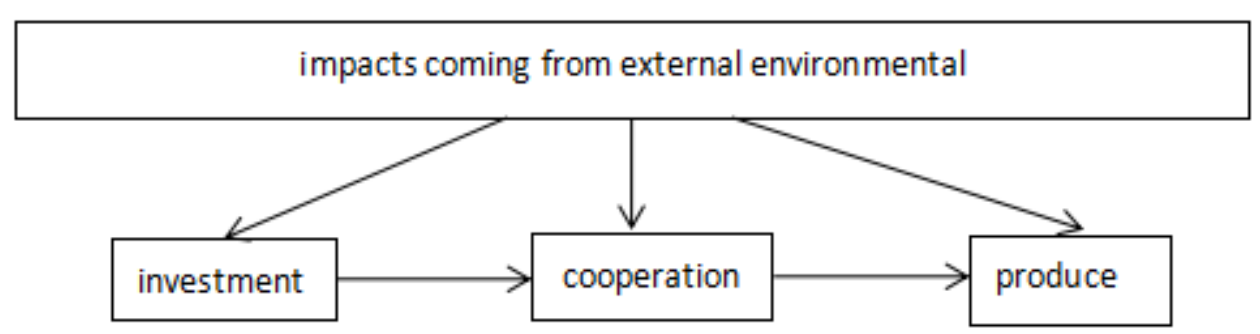

Fig.2 The Output Mechanism of Team Performance

Team is a diverse staff composition, so in terms of investment in the team, it contains a difference characteristics of each individual member, and a common vision for information exchange between individuals. Under the influence of external organizational culture, enterprise system and other environmental factors, through a complex series of cooperation transmission of information flow, it eventually forms a team achievement. Thus, team-based performance management can not copy individual performance management system, instead, it needs to do the following three points in the maintenance of traditional performance management cycle process: First, it is necessary to fully consider the external environment and other factors that affect team performance output, because it can build healthy competition corporate culture that encouraging team innovation. Second, the work should focus on how scientifically and effectively to measure team performance. Third, to maintain an exchange among the teams to fully feedback the performance results of team members. 
Performance management for key employees. Core employee performance management should be the focus of enterprise performance management. Firstly, performance management is a process of two-way communication, and the key employees' performance management should focus on the management and strengthening communication. The core staff of the enterprise are usually the knowledge workers, in the performance management, it is a difficult to quantify the assessment index, and the process of fair perception is not high. Therefore, the core staff of the performance management should be clear the whole process of performance management, from the target set to the results feedback, it should be transparent and open. Encourage core employees to participate in the whole process of performance management, especially in the setting of performance measures to reach a consensus. Therefore, core employee performance management should closely linked with other human resources management module. Strengthen the performance of the incentive, and timely feedback to the core staff, and put the results as an important basis for personal training and development, incentive pay and career promotion.

Performance management for executives. Performance management is a business process that needs full participation, in goal-setting session, the companies develop strategies should be broke down to individual employees, in the evaluation phase of the assessment results and feedback, the examination results required to report to the hands of business executives from the bottom to provide comprehensive data for policy makers. The significance of senior management performance management is more important than the general staff. On the one hand, performance management for executives is a very good self-examination and reflection process; On the other hand, performance management also enables high-level play an exemplary role in employees, the executives' performance feedback results should be combined with compensation and long-term incentives.

\section{Conclusion}

Performance management thinking, theory and practice coexist, since the establishment of its scientific system, it has more than half a century, in the development of this half-century, all aspects of performance management have undergone tremendous changes. Performance management improvement and innovation has been around how to achieve corporate strategic objectives through performance management. Performance management change is a long-term and coherent, and the innovative advantages will continue to highlight in the transformation.

\section{Reference}

[1] Yang Guohua. An analysis of the implementation of the performance management of state-owned enterprises and the reform of innovative strategies [J]. brand (theoretical monthly), 2011,03:46-47.

[2] Zhang Haibing. Problems existing in the current enterprise performance management and the analysis of the reform and innovation [J]. China management information, 2015,24:96.

[3] Huang Chunhong. A discussion on the reform of the wage system and the performance management of enterprises [J]. China's foreign investment, 2012,11:197+2. 
[4] Liu Mingjian. Mode innovation of performance management of tourism enterprises [J]. China human resources development, 2005,08:56-59. 